\section{THE BUSINESS SIDE OF A PHYSICIAN'S LIFE.*}

H. BROOKER MILIS, M.D. PHILADELPHIA.

So far as reviewing the work of the past year is concerned, I would only like to call your attention to the excellent work done by both the scientific business and membership committees, together with the faithful work of the secretary and the hearty co-operation of the members. I feel that our programs have always been a credit to the society; our attendance has been on a gradual increase; our membership roll has increased rapidly, and our benefit to the profession at large has been more felt than ever before. That the branch movement in the county medical society was a good one, has b cen well proved by the past two years' work of our own branch, and not only has it been the means of causing a great deal of good work to be done, but it has also shown us in what direction much more needs to be done. The experience of the last two years has borne excellent fruit in the way of organizing the medical profession in this city, as well as stimulating its organization in other parts of the country, and I feel the work already accomplished probably far exceeds the expectations of the prime movers in this work, both of whom have been and are ardent supporters of our own branch, i. e., Drs. Eaton and Hirsh.

I thought I would discuss for a few moments this evening the subject of physicians' relations, and desire to do so under the heading of relations to, first, their patients; second, their fellow-members of the profession, especially conqultants; and last but not least, to themselves.

As to the physician's relations to his patients, the views are so widely different and the relevant subjects so numerous that any concise expression of opinion is out of the question, but after conversing with physicians and the laity on the subject, I have come to the conclusion that much misunderstanding frequently exists between the physician and his patient as to the proper relation the one bears to the other, sufficient in many cases to work to the detriment of the patients. Such questions as the following all have a bearing on the subject under discussion:

Should a physician go out at night to treat a case in a family already owing him a large bill without any prospect of payment?

Should he treat a case recently involuntarily given up by another physician, when, in his opinion, the other physician has been unjustly discharged?

Should he adopt any of the measures commonly used by business men for the collection of his bills?

Should he undertake to treat at home, amid unfavorable surroundings, the cases which positively need hospital treatment in order to have any chance of recovery?

Should he regulate his charges according to the means of the family treated?

In fact, these have so much bearing on the subject that the last-named query has been frequently a subject of discussion in both the medical and lay press very recently. To decide these questions, the physician must either act as a physician or as a man, and his decision will be widely different, depending on which point of riew he takes. While I know of cases where the purely human side has dominated, frequently to the physician's

- Address of the retiring chairman of the North Branch of the Philadelphia County Medical Society, Jan. 14, 1904. loss, vet I am sure that there are many where a purely medical side has decided the matter, not unfrequently to the patient's loss. The great question to my mind is : Can not the two sides be so commingled diplomatically that at least, in a majority of cases, neither side is the material loser? And I have come to the conclusion that the solution of the problem lies in one thing, and that is the training of the patient by the physician, which I admit is more an art than a science. In many cases the properly trained patient can be induced to avoid allowing bills becoming too large, often obviate calling the Doctor late at night, and not to become dissatisfied on slight provocation, and seek advice elsewhere on the spur of the moment, and I know of several prominent physicians in this city who can personally testify to the great advantages to be derived from what they term "The Training of the Patients." Particularly is this true in reference to the question of fees, and many of the controversies, especially such as have frequently become public on the question of charge, could be avoided, did the physician, in the first place, possess, and in the second, make more intelligent use of, a sufficient amount of business knowledge to practically as well as scientifically deal with the sick.

As to the second point, that of the physician's relations to the fellow-members of the profession and especially consultants, this again is a broad subject and one which is capable of much abuse. Did we but act and feel at all times toward our fellow-practitioners as we do toward our patients and were we always as anxious to retain the esteem of the former as the good will of the latter, I feel we should frequently be much more considerate in our expressions and more liberal in our views. In the same way as some of our poorest patients have proven to be our best practice builders, some of the apparent unknown members of the profession have proven to be the stepping-stones to at least fortune, if not fame, of some of the leading members of the profession to-day.

It is, therefore, a matter for serious thought as to, 1, the time to ask for consultation; 2 , who to ask for, and 3 , what shall be done with the fee.

I personally feel entirely incompetent to express any weighty opinion on this subject, but if data obtained by conversation, correspondence and reading, plus a small amount of experience count for anything, it certainly does enable me to express the opinion that the consultant's fee belongs to him and him alone. Here, again, arises the question as to the fee to be charged, and it does seem to me only justice that the consultants should be willing to consult for whatever fee the attending physician believes to be the maximum of the patient's ability to pay, and this once agreed on, should be looked on as the property of the consultant exclusively. A question not unfrequently asked, where this fee is not paid at time of the consultation, but is made to form part of the total bill for services rendered for that illness, is, should the attending physician pay the consultant in full out of the first moneys received, or divided out pro rata between the consultant and himself? And as much data as I have been able to collect on this subject, when boiled down yields a majority opinion in favor of the first proposition, i. e., the full as well as prompt payment of the consultant. This seems only fair, when one considers that should nothing ever be paid for any of the services rendered, the attending physician would not feel under any obligation to personally pay the consultant, which $I$ think is an additional 
reason why the latter should receive his fee out of the first payment made.

The third and last question, that of the physician's relations to himself, would probably be more carefully expressed if it was called "his duty to himself." The overworked, partly fed and half-rested physician can not do justice to those entrusted to his care, nor is his zealous application to the relief of the suffering of others sufficientily understood to be appreciated by a large majority, especially of the suffering laity. The natural inborn selfishness of the human race, plus, as before mentioned, the lack of a proper training, added to more or less pain, not only obscures keen perception, but also benumbs the highest sensibilities of the rights of others sufficient to make very arduous if not well nigh impossible the satisfactory filling of the duties of the medical practitioner of to-day. In brief, the conclusion from this third and last question is that the medical man of to-day should make himself more a living example of the fruits of preventative medicine, in order to better fit himself to practice the art of scientific mediicine.

In concluding this brief and as yet incomplete address, I desire to thank the members as sincerely and heartily for their uniform courtesy and kindness to me during my term as chairman, as I did and do again for honoring me with the election one year ago, and to take the liberty of asking for my. successor a continuance of that same leniency and consideration, which has enabled one so poorly fitted for the position to close his term of office with the branch in such a satisfactory condition as the North Branch is to-day.

\section{SURGICAL TREATMENT OF PULMONARY ABSCESS.* \\ VAN BUREN KNOTT, M.D. SIOUX CITY, IOWA.}

As the surgical treatment of pulmonary abscess still presents many difficulties to be overcome and problems for solution, the personal experience of operators in this line of work, even though that experience is limited, will be of assistance in formulating rules for future guidance.

No résumé of the literature will be attempted, as several scholarly articles published during the past two years have anticipated and rendered unnecessary such a procedure.

Experience has demonstrated that multiple lung abscesses and those accompanied by bronchiectasis are, as a rule, not benefited by operation. Tubercular abscesses and those due to the presence of a foreign body in the lung will not be considered, as they present complications placing them in classes by themselves, and with their surgical treatment I have had no experience. Metastatic and embolic lung abscesses are multiple and not amenable to surgical treatment.

This leaves for our consideration those cases of single pulmonary abscesses the sequelæ of pneumonia, with which may also be included those rare cases due to rupture into the lung of abscesses of the liver, those of appendicular origin, etc. These may be roughly divided into two classes, acute and chronic, and may or may not be accompanied by gangrene and bronchiectasis. As the mortality following surgical treatment of cases so complicated is fully twice as great as that of the simple

* Read at the Thirteenth Annual Meeting of the Western Surg ical and Grnecological Association, held at Denver, Dec. 28-29, 1903. cases, it is urged that these patients be given the better chance which is offered by timely surgical intervention.

With the general symptoms and diagnosis of pulmonary abscess there exists equally general familiarity. The surgeon will not, as a rule, see these cases until the diagnosis has been made by the internist, who has been in attendance and will be called on not so much to make a diagnosis of abscess as to determine its exact location, with the hope of surgical relief. This may be at times extremely difficult and often impossible.

In two cases which I have seen and which will be referred to again, although the patients presented all the symptoms common to abscess of the lung and the physician in attendance, as well as I, was satisfied of its existence, we were only able to locate it in the one case at the autopsy, and in the other suffered the indignity of having our diagnosis confirmed and our failure to locate the abscess accentuated by its rupture into the pleural cavity with empyema as the penalty.

While in many quarters attempts to locate the abscess by aspiration have been denounced as unsafe and injudicious, my limited experience has taught me the inadvisability of attempting to open an abscess of the lung without the aspirator as a guide. The physical signs common to this condition in many cases are alone not sufficient to render its exact localization possible, and, while we may be satisfied that in a given instance the lung contains an abscess and from the usual methods of examination have decided as to its location, this point should be positively corroborated by the aspirator before proceeding with the operation. In Case 2, reported below, I was so certain of the existence of an abscess in the lower lobe of the left lung that, despite my failure to locate it with the aspirator, I exposed the suspected area and subjected the patient to a severe and prolonged operation during my fruitless search for the pus. "Fortunately, in the greater number of these cases, pleural adhesions are present so that unless repeated punctures are made, some of which may be beyond the area so protected, the danger of extravasation is slight.

In cases where the history and physical signs lead us to suspect pulmonary abscess, the localization must be made as accurately as possible by the usual and wellunderstood methods of examination. The patients should then be prepared for operation, and under local anesthesia an attempt to aspirate the abscess is made. The aspirator, which should carry a short needle of good caliber, should be introduced at the center of the suspected area, as at this point the protecting adhesions are most likely to be present. If pus is not found at this first attempt the needle should not be withdrawn completely from the lung, but as nearly so as possible and reinserted in varions directions until it enters the cavity. This will prevent the multiple punctures of the pleura and diminishes the danger of extravasation of septic material into the pleural cavity.

When pus is found the needle should be left as a guide and chloroform administered, it being in the class of cases under consideration preferable to ether. A free incision, rendered so by the partial resection of at least two ribs, should then be made, well exposing the diseased area.

Pleural adhesions will usually be found present over the surface sufficiently large for the purpose. If absent the pleura must be sutured with catgut, using the common "back stitch." The suture line is then reinforced with iodoform gauze packing and the operation may be 